University of South Carolina

Scholar Commons

$8-2000$

\title{
Children's Understanding of the Concept of Physical Activity
}

Stewart G. Trost

Angela M. Morgan

Ruth P. Saunders

Gwen A. Felton

Dianne S. Ward

See next page for additional authors

Follow this and additional works at: https://scholarcommons.sc.edu/

sph_physical_activity_public_health_facpub

Part of the Public Health Commons

\section{Publication Info}

Published in Pediatric Exercise Science, Volume 12, Issue 3, 2000, pages 293-299.

Trost, S. G., Morgan, A. M., Saunders, R., Felton, G., Ward, D. S., \& Pate, R. R. (2000). Children's understanding of the concept of physical activity. Pediatric Exercise Science, 12(3),293-299. (C) Pediatric Exercise Science, 2000, Human Kinetics

This Article is brought to you by the Physical Activity and Public Health at Scholar Commons. It has been accepted for inclusion in Faculty Publications by an authorized administrator of Scholar Commons. For more information, please contact digres@mailbox.sc.edu. 


\section{Author(s)}

Stewart G. Trost, Angela M. Morgan, Ruth P. Saunders, Gwen A. Felton, Dianne S. Ward, and Russell R.

Pate 


\title{
Children's Understanding of the Concept of Physical Activity
}

\section{Stewart G. Trost, Angela M. Morgan, Ruth Saunders, Gwen Felton, Dianne S. Ward, and Russell R. Pate}

\begin{abstract}
This study evaluated 4th-grade students' understanding of the concept of physical activity and assessed the effects of two interventions to enhance the students' understanding of this concept. Students were randomly assigned to 1 of 3 conditions: the video group $(n=40)$ watched a 5-min video describing physical activity; the verbal group $(n=42)$ listened to a generic description of physical activity; the control group received no instruction $(n=45)$. Students completed a 17-item checklist testing their understanding of the concept of physical activity. Compared to controls, students in the verbal and video group demonstrated significantly higher checklist scores, with the video group scoring significantly higher than the verbal group. Only $35.6 \%$ of the controls, compared to $52.4 \%$ and $70.0 \%$ of the verbal and video groups respectively, could classify $\geq 15$ of the checklist items correctly. The results indicate that, without intervention, children have a limited understanding of the concept of physical activity.
\end{abstract}

Promotion of lifelong physical activity among children and adolescents has become a priority area for public health authorities $(2,9,10)$. Accordingly, there is a need for precise, well-validated measures of youth physical activity $(10,15)$. To date, a wide range of methods have been used to quantify physical activity behavior in children and adolescents. These include self-report questionnaires, direct observation, heart rate monitoring, motion sensors, and doubly labeled water (5). However, due to their low cost and ease of administration, self-report questionnaires are the most commonly used method for assessing physical activity behavior in population-based research $(5,16)$.

While less burdensome than objective measures, assessing physical activity behavior via self-report is recognized to be more difficult for children than adults (13). In addition to problems associated with recall limitations and social desir-

S.G. Trost, A.M. Morgan, D.S. Ward, and R.R. Pate are with Department of Exercise Science in the School of Public Health at the University of South Carolina, Columbia, SC 29208. R. Saunders is with the Department of Health Promotion and Education in the School of Public Health at the University of South Carolina. G. Felton is with the Department of Family and Community Nursing in the School of Nursing at the University of South Carolina. 
ability $(12,13,16)$, it is unclear whether young children fully understand the concept of physical activity. In the research literature, the term physical activity is operationally defined as any bodily movement produced by skeletal muscle that results in energy expenditure (8). However, because of the prominent role of individual fitness activities and organized sports in schools, homes, and the mass media, it is conceivable that many children associate the term physical activity with participation in organized sports such as soccer and basketball and/or fitness activities such as calisthenics, weight training, and aerobic dance $(6,7)$. Consequently, when children are asked to recall their past physical activity behavior or respond to items questioning their attitudes and beliefs about physical activity, it is possible that potentially important sources of physical activity such as playing active games, walking to school, and household chores are not taken into account. In addition, because many youngsters may not adequately understand the concept of physical activity, sedentary activities such as playing video games and working on a computer may erroneously be considered to be physical activity.

Despite the seriousness of such errors, the extent to which young children understand the concept of physical activity has not been previously examined. Furthermore, it remains unclear whether simple interventions such as verbal explanations of physical activity or more elaborate measures such as instructional videotapes depicting physical activity are effective in enhancing children's understanding of the concept of physical activity. Hence, the aims of this study were to: (a) evaluate the completeness of fourth-grade students understanding of the concept of physical activity; and (b) assess the effects of two interventions designed to enhance the students' understanding of the concept of physical activity.

\section{Methods}

\section{Subjects}

The study group consisted of 127 fourth-grade students from two elementary schools in rural South Carolina. The sample was $45 \%$ female and $40 \%$ African-American. Prior to participation in the study, written informed consent was obtained from each participant and his or her primary guardian. Protocol requirements established by the University of South Carolina School of Public Health Ethics Committee were satisfied prior to data collection.

\section{Experimental Design}

Participants were randomly assigned to one of three experimental conditions: a video group $(n=40)$, a verbal group $(n=42)$, and a control group $(n=45)$. Students in the video group watched a 5-min instructional video showing various forms of physical activity including competitive sports (basketball, football, baseball, volleyball), fitness activities (jogging, cycling), fun activities (skateboarding, playing in the playground, dancing), transportation activities (walking and riding a bike to school), and household chores (vacuuming, mowing the lawn, raking leaves). The video did not provide examples of sedentary activities. Students in the verbal group were read the following description of physical activity: "Physical activity is any play, game or sport that gets you moving, breathing faster, and your heart beating faster." While such an abbreviated description has obvious shortcomings, it was chosen because it approximates the description of physical activity appearing on 
most questionnaires used with children and adolescents $(4,17-19)$. Students in the control group received no instruction as to the definition of physical activity. This experimental condition was included to: (a) provide a means of assessing the relative efficacy of the video and verbal interventions, and (b) explore children's "natural" level of understanding of the concept of physical activity.

\section{Physical Activity Checklist}

Following each treatment, students completed a physical activity checklist that asked them to classify 17 commonly performed activities as physical activity or not physical activity. Scores were expressed as the total number of correct responses. All treatments and checklists were administered by the same research assistant. The physical activity checklist and descriptive statistics for each item are shown in Table 1.

\section{Development of the Physical Activity Checklist}

Items appearing on the checklist were generated from a qualitative pilot study in which 25 fourth-grade children were asked to write down what they thought was physical activity and what was not physical activity. From these written responses, a preliminary checklist consisting of 28 activities was constructed and administered to an independent sample of 205 demographically similar students. Following the calculation of descriptive statistics for each item and assessment of item to total score correlations, the number of items on the checklist was reduced from

Table 1 Descriptive Data for Items Appearing on the Physical Activity Checklist

\begin{tabular}{|c|c|c|c|c|}
\hline \multirow[b]{2}{*}{ Item } & \multirow{2}{*}{$\begin{array}{l}\text { Correct } \\
\text { response }\end{array}$} & \multicolumn{3}{|c|}{ Percentage of correct responses } \\
\hline & & Control & Verbal & Video \\
\hline Walking to school is physical activity. & Yes & 86.7 & 73.8 & 100 \\
\hline Riding the school bus is physical activity. & No & 86.7 & 100 & 100 \\
\hline Running around the yard is physical activity. & Yes & 97.8 & 100 & 97.5 \\
\hline Reading a book is physical activity. & No & 62.2 & 97.6 & 82.5 \\
\hline Raking the leaves is physical activity. & Yes & 84.4 & 71.4 & 100 \\
\hline Working on the computer is physical activity. & No & 62.3 & 97.6 & 74.4 \\
\hline Baseball is physical activity. & Yes & 100 & 97.6 & 100 \\
\hline Sitting in class is physical activity. & No & 88.9 & 100 & 97.5 \\
\hline Cleaning my room is physical activity. & Yes & 71.1 & 69.1 & 97.5 \\
\hline Singing a song is physical activity. & No & 62.2 & 97.6 & 79.5 \\
\hline Playing video games is physical activity. & No & 66.7 & 85.2 & 77.5 \\
\hline Vacuuming the carpet is physical activity. & Yes & 68.9 & 45.2 & 92.5 \\
\hline Doing homework is physical activity. & No & 64.4 & 85.7 & 74.9 \\
\hline Climbing trees is physical activity. & Yes & 93.3 & 85.7 & 97.5 \\
\hline Doing household chores is physical activity. & Yes & 80.0 & 73.8 & 97.5 \\
\hline Eating dinner is physical activity. & No & 68.9 & 95.2 & 71.8 \\
\hline Sweeping the floor is physical activity. & Yes & 71.1 & 52.4 & 92.5 \\
\hline
\end{tabular}


28 to 17 . Eight of the 17 items included on the checklist were sedentary activities as defined by the Compendium of Physical Activities (1). For the present study, the internal consistency of the Physical Activity Checklist as measured by Cronbach's alpha was 0.84 .

\section{Statistical Analysis}

Differences in the number of correct responses on the physical activity checklist across the three treatment conditions were tested using a one-way ANOVA. Upon a significant $F$-ratio, a Student-Newman-Keuls multiple range test was used to determine the location of significant pairwise differences. In addition, the percentage of students in the control, verbal, and video groups with $\leq 10$ correct responses, 11 to 14 correct responses, and $\geq 15$ correct responses were compared using a chisquare test. Statistical significance for this study was set at an alpha of 0.05 .

\section{Results}

On average, students in the video group $(15.3 \pm 1.6)$ classified significantly more checklist items correctly than those in the verbal (14.4 \pm 2.3$)$ and control groups $(13.1 \pm 2.9)$. Checklist scores for the control group were significantly lower than either the video and verbal groups. The percentage of students in each group with $\leq 10$ correct responses, 11 to 14 correct responses, and $\geq 15$ correct responses on the checklist is shown in Figure 1. Students in the video group were significantly more likely than students in the verbal or control groups to score $\geq 15$ on the checklist. Conversely, students in the control group were significantly more likely than students in the video or verbal groups to score $\leq 10$ on the checklist. In fact, no students in the video group scored $\leq 10$ on the checklist.

\section{Discussion}

Presently, the cognitive processes underlying the recall of past physical activity behavior in children and adolescents remain poorly understood $(4,11)$. A key issue which remains inadequately explored is whether or not elementary school-aged children adequately understand the concept of physical activity $(6,7)$. That is, in addition to traditional sports and recreational activities, do young children think of walking or bicycling to school and household chores such as sweeping the floor as physical activity? Our findings suggest that, without prior intervention, fourthgrade students demonstrate a limited understanding of the concept of physical activity as currently defined by researchers and heaith practitioners. On average, students who received no instruction as to the definition of physical activity were able to correctly classify approximately 13 of the 17 items appearing on the physical activity checklist, which was significantly lower than students receiving either the video or verbal interventions. Moreover, only $35.6 \%$ of the students in the control group, compared to $52.4 \%$ and $70.0 \%$ of the students in the verbal and video groups, were able to classify 15 or more of the checklist items correctly. Of note, $37.8 \%$ of the children in the control group indicated that working on the computer was physical activity, while approximately $30 \%$ thought sweeping the floor was not physical activity. For those receiving the verbal explanation, just over $30 \%$ thought sitting in class was physical activity, while more than $50 \%$ thought 


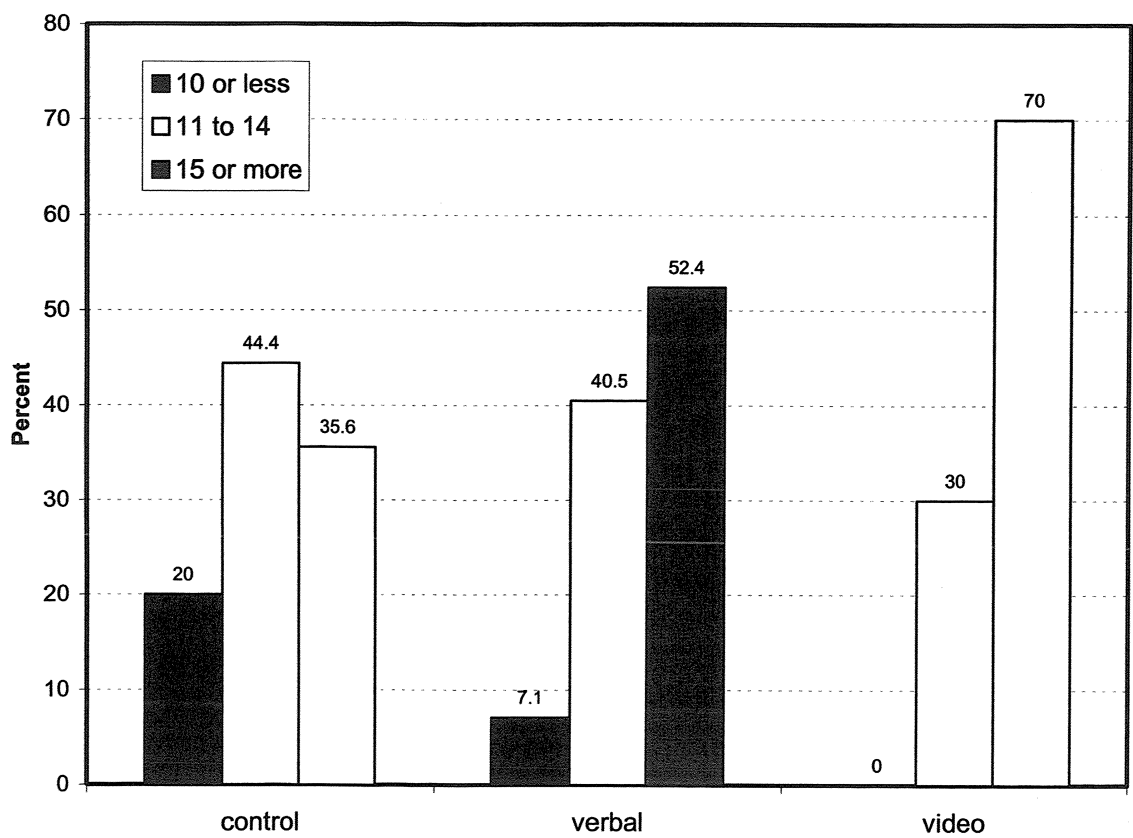

Figure 1 - The percentage of students in each group with $\leq 10$ correct responses, 11 to 14 correct responses, and $\geq 15$ correct responses on the physical activity checklist $\left(\chi^{2}=\right.$ $10.07,2 d f, p<.01)$.

vacuuming the carpet was not physical activity. Clearly, such errors pose a threat to validity in studies assessing energy expenditure and/or the personal, social, and environmental factors associated with participation in physical activity.

A key question in this study was whether or not interventions designed to enhance children's understanding of the term physical activity were effective. Our results indicate that both the generic verbal description and instructional video were effective in helping students understand the meaning of physical activity, with the instructional video being more effective than the verbal description. This finding has important implications for physical activity-related research involving elementary school-aged children. When quantifying individual physical activity behavior, or alternatively, assessing the personal, social, and environmental factors associated with participation in physical activity, it is important that the concept of physical activity be adequately defined for students. While our data confirm that a very brief verbal description will help youngsters understand the concept of physical activity, a more specific, visually oriented presentation such as an instructional video appears to be more effective at helping students understand the broad concept of physical activity.

This study had several limitations that warrant consideration. First, because of the small sample size, we were unable to examine racial/ethnic or gender differences in physical activity checklist scores. Second, because the verbal and video interventions differed greatly in "prep time" and level specificity, we were unable to determine whether differences in the medium alone accounted for the observed 
differences between the intervention groups. Yet, within these limitations, our results provide important information as to children's understanding of the term physical activity. Our findings may have particular significance to researchers and practitioners wishing to promote physical activity in young children via mass-media campaigns (e.g., television and radio advertisements).

In conclusion, the results of this study suggest that fourth-grade students demonstrate a limited understanding of the concept of physical activity. Simple interventions such as showing a 5-min video depicting different forms of physical activity appear to be effective in helping students understand the concept of physical activity. Future studies should examine the efficacy of longer, more detailed verbal descriptions that include group discussions about the term physical activity, as well as explore potentially important gender and race/ethnicity differences in children's understanding of the concept of physical activity.

\section{References}

1. Ainsworth, B.E., W.L. Haskell, A.S. Leon, D.R. Jacobs Jr., H.J. Montoye, J.F. Sallis, and R.S. Paffenbarger. Compendium of physical activities: classification of energy costs of human physical activities. Med. Sci. Sports Exerc. 25:71-80, 1993.

2. American Medical Association. AMA Guidelines for Adolescent Preventive Services (GAPS): Recommendations and Rationale. Baltimore: Williams and Wilkins, 1993.

3. Andersen, R.E., C.J. Crespo, S.J. Bartlett, L.J. Cheskin, and M. Pratt. Relationship of physical activity and television watching with body weight and level of fatness among children. JAMA 279:938-942, 1998.

4. Baranowski, T. Validity and reliability of self-report measures of physical activity: an information-processing perspective. Res. Q. Exerc. Sports. 59:314-327, 1988.

5. Baranowski, T., C. Bouchard, O. Bar-Or, T. Bricker, G. Health, S.Y.S. Kimm, R. Malina, E. Obarzanek, R.R. Pate, W.B. Strong, B. Truman, and R. Washington. Assessment, prevalence, and cardiovascular health benefits of physical activity and fitness in youth. Med. Sci. Sports Exerc. 24(Suppl.):S237-S247, 1992.

6. Brustad, R.J. Children's perspectives on exercise and physical activity: measurement issues and concerns. J. Sch. Health 61:228-230, 1991.

7. Cardinal, B.J., H.J. Engels, and W. Zhu. Application of the transtheoretical model of behavior change to preadolescents' physical activity and exercise behavior. Pediatr. Exerc. Sci. 10:69-80, 1998.

8. Caspersen, C.J., K.E. Powell, and G.M. Christensen. Physical activity, exercise, and physical fitness: definitions and distinctions for health-related research. Public Health Rep. 100:126-131, 1985.

9. Center for Disease Control and Prevention. Guidelines for school and community programs to promote lifelong physical activity among young people. MMWR. 46:(RR-6), 1997.

10. Department of Health and Human Services. Physical Activity and Health: A Report of the Surgeon General. Atlanta, GA: U.S. Department of Health and Human Services, Centers for Disease Control and Prevention, National Center for Chronic Disease Prevention and Health Promotion, 1996.

11. Durante, R., and B.E. Ainsworth. The recall of physical activity: using a cognitive model of the question-answering process. Med. Sci. Sports Exerc. 28:1282-1291, 1996.

12. Freedson, P.S. Electronic motion sensors and heart rate as measures of physical activity in children. J. Sch. Health 61:220-223, 1991. 
13. Pate, R.R. Physical activity assessment in children and adolescents. Crit. Rev. Food Sci. Nutr. 33:321-326, 1993.

14. Public Health Service. Healthy People 2000: National Health Promotion and Disease Prevention Objectives (DHHS Publication No. PHS 91-50212). Washington, DC: U.S. Department of Health and Human Services, 1990.

15. NIH Consensus Development Panel on Physical Activity and Cardiovascular Health. Physical activity and cardiovascular health. JAMA 276:241-246, 1996.

16. Sallis, J.F. Self-report measures of children's physical activity. J. Sch. Health. 61:215219, 1991.

17. Sallis, J.F., P.K. Strikmiller, D.W. Harsha, H.A. Feldman, S. Ehlinger, E.J. Stone, J. Williston, and S. Woods. Validation of interviewer- and self-administered physical activity checklists for fifth grade students. Med. Sci. Sports Exerc. 28:840-851, 1996.

18. Saunders, R.P., R.R. Pate, G. Felton, M. Dowda, W.C. Weinrich, D.S. Ward, M. Parsons, and T. Baranowski. Development of questionnaires to measure psychosocial influences on children's physical activity. Prev. Med. 26:241-247, 1997.

19. Zakarian J.M., M.F. Hovell, C.R. Hofstetter, J.F. Sallis, and J.C. Keating. Correlates of vigorous exercise in a predominantly low SES and minority high school population. Prev. Med. 23:314-324, 1994.

\section{Acknowledgements}

This research was funded by the National Institutes of Health RO1 NR 03634-01. 